TRABAJOS DE PREHISTORIA

66, N. ${ }^{\circ}$ 2, julio-diciembre 2009, pp. 45-60, ISSN: 0082-5638

doi: $10.3989 /$ tp.2009.09021

\title{
Balma Guilanyà (Prepirineo de Lleida) y el Aziliense en el noreste de la Península Ibérica
}

\author{
Balma Guilanyà (Prepyrenees of Lleida) and the Azilian at the North-East of Iberia
}

\author{
Jorge Martínez-Moreno (*) \\ Rafael Mora Torcal $\left(^{*}\right)$
}

\begin{abstract}
RESUMEN
Guilanyà es un asentamiento localizado en las primeras estribaciones del Prepirineo de Lleida, a $1.150 \mathrm{~m} \mathrm{de}$ altitud. En este artículo se exponen las observaciones preliminares derivadas de un sondeo realizado en el verano del 2008, que ha permitido definir los niveles arqueológi$\cos \mathrm{K}$ y EJ. Paralelamente, se presentan nuevas dataciones por ${ }^{14} \mathrm{C}$ AMS que contextualizan cronométricamente la secuencia Tardiglaciar de este yacimiento. Estos resultados permiten identificar la gestión recurrente de los ecosistemas de montaña durante la mejora Bolling/Allerod. Las características tecno-tipológicas que se reconocen en estos niveles nos permiten asignarlos al Aziliense, tradición cultural escasamente visualizada en la vertiente sur de los Pirineos.
\end{abstract}

\begin{abstract}
Balma Guilanyà is a rock-shelter located more than 1,150 metres asl, in the South-Eastern Pre-Pyrenees of Lleida. The test pit carried out during the summer of 2008 yielded the archaeological levels $K$ and EJ, which can be correlated with the Bolling/Allerod climatic amelioration. In this paper, new 14C AMS dates are presented and contextualised within the sequence of the Late Glacial in the South-Eastern Pyrenees. Preliminary results also permit the identification of techno-typological characteristics of the Azilian, a chrono-cultural tradition poorly known in the North-East of the Iberian Peninsula.
\end{abstract}

Palabras clave: Balma Guilanyà; Prepirineos Surorientales; ${ }^{14} \mathrm{C}$; niveles $\mathrm{K}$ y EJ; Bolling/Allerod; Aziliense.

Key words: Balma Guilanyà; South-Eastern Pre-Pyrenees; 14C; $K$ and EJ levels; Bolling/Alllerod; Azilian.

(*) Centre d'Estudis del Patrimoni Arqueològic de la Prehistoria. Facultat de Lletres. Universitat Autònoma de Barcelona. 08193 Bellaterra.

Correo electrónico: jorge.martinez@uab.cat.

Recibido: 13-II-2009; aceptado: 8-VII-2009.

\section{EL TARDIGLACIAR DE LA VERTIENTE SUR DE LOS PIRINEOS ORIENTALES}

Desde el Centre d'Estudis del Patrimoni Arqueològic de la Prehistòria de la Universitat Autònoma de Barcelona venimos desarrollando una línea de investigación dirigida a analizar las pautas relacionadas con la instalación humana, a lo largo del Pleistoceno superior y Holoceno inicial, en la vertiente suroriental del Pirineo. En los últimos años han aumentado las secuencias arqueológicas que registran la presencia humana en el contacto entre el arco pirenaico y el valle del Ebro al final del Pleistoceno, tal y como indican Chaves, Forcas 1, Alonsé, y Fuente del Trucho en Huesca (Utrilla y Montes 2007); o Cova del Parco (Mangado et al. 2007) y Cova Gran de Santa Linya (Martínez-Moreno et al. 2008a) en Lleida. Dentro de este creciente número de asentamientos, merece mencionarse Montlleó que señala el tránsito de grupos humanos por el altiplano de la Cerdanya durante el Pleniglaciar (Mangado et al. 2006), y los enclaves de montaña como Balma Margineda (Andorra) en el Pirineo Axial (Guilaine y Martlzuff 1995, 2007) y Balma Guilanyà en el Prepirineo de Lleida (Fig. 1) (Casanova et al. 2007).

Se ha indicado que los asentamientos de montaña permiten examinar las transformaciones que afectan a la organización de los cazadores-recolectores del final del Pleistoceno (Straus 1987). La fragmentación de los paisajes de montaña propicia medios con una alta biodiversidad que proveen de una amplia gama de plantas y animales, susceptibles de ser explotados durante breves ventanas estacionales. En consecuencia, la presencia humana en estos medios requiere una importante planificación de las actividades que 


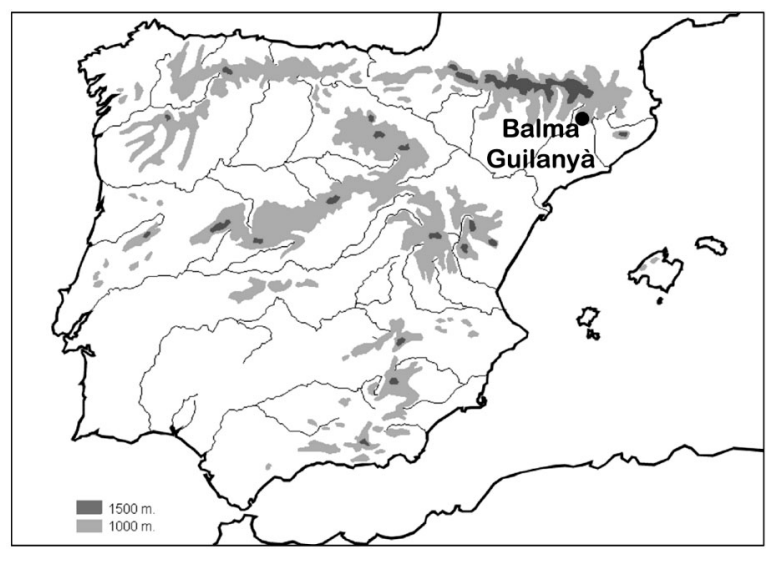

Fig. 1. Localización de Balma Guilanyà (Navès, Prepirineo de Lleida).

finalmente determinan el cuándo y el cómo acceder a esos entornos en los que se obtienen abundantes recursos, aunque sólo disponibles en restringidos intervalos temporales (Gamble 1993).

En este artículo se exponen las implicaciones iniciales que se derivan del sondeo realizado en Balma Guilanyà durante el verano del 2008. Estas inferencias permiten proponer varias hipótesis sobre las estrategias que desarrollan los cazadores-recolectores del noreste de la Península Ibérica, y que en paralelo trazan la expansión humana por unos entornos constrictivos como los que debían representar los ecosistemas de montaña de los Pirineos al final del Pleistoceno.

Estas observaciones se comparan y complementan con las informaciones que aporta la reciente publicación de los niveles tardiglaciares de Margineda (Guilaine y Martlzuff 2007). Consideramos que las tendencias detectadas en estos dos asentamientos promueven argumentos con los que analizar la organización de la subsistencia en la vertiente surpirenaica durante la mejora Bolling/Allerod. Al mismo tiempo, las características generales de los conjuntos líticos de estos yacimientos del Pirineo suroriental permiten su adscripción al Aziliense, tradición crono-cultural escasamente señalada en el noreste de la Península Ibérica.

\section{GUILANYÀ: UN PEQUEÑO ABRIGO "PERDIDO" EN EL PREPIRINEO SURORIENTAL}

Balma Guilanyà es un asentamiento a $1.157 \mathrm{~m}$ de altitud $(X=385087 \mathrm{Y}=4660546$, UTM H31N
ED50) que se localiza en la Serra de Busa, el primer contrafuerte del Prepirineo del Solsonès (Navès, Lleida). Este abrigo se localiza bajo una visera de conglomerados adyacente a un pequeño valle construido por el Torrent de Ventolrà, un arroyo que conecta el Plà de Busa -un altiplano en el techo de la Serra de Busa, a $1.500 \mathrm{~m}$ de altitud- con la Depresión Central Catalana y Valle del Ebro, planicies que se extienden al pie de la vertiente surpirenaica (Fig. 1).

El yacimiento fue descubierto en 1992, debido a la construcción de una pista forestal que dejó al descubierto una secuencia arqueológica en la que se determinan dos momentos crono-culturales distintos: la unidad superior adscrita al Mesolítico y la unidad inferior atribuida al Paleolítico superior final (Parcerisas et al. 2003). Actualmente identificamos 5 unidades arqueológicas: en la unidad superior dos niveles del Holoceno $-\mathrm{C}$ y $\mathrm{C} 1-$, y en la unidad inferior tres ocupaciones tardiglaciares $-\mathrm{E}$, EJ y $\mathrm{K}-$ - (Fig. 2). La dispersión vertical del material coordenado define palimpsestos arqueológicos generados por la ocupación reiterada del abrigo durante una amplia escala temporal, que puede acotarse radiométricamente.

En este artículo nos centraremos en el registro arqueológico recuperado en las unidades EJ y K, para las que se disponía de un limitado conocimiento. Esta descripción complementa los resultados referidos a la secuencia mesolítica $(\mathrm{C}$ y C1) y el primer nivel tardiglaciar (E), objeto de diversas aportaciones (Martínez-Moreno 2006a; Casanova et al. 2007). Al mismo tiempo, se presentan 4 nuevas fechas ${ }^{14} \mathrm{C}$ AMS para la secuencia tardiglaciar. De esta nueva serie, dos se obtuvieron a partir de la datación directa de restos humanos recuperados en el nivel E. Estos resultados permiten realizar varias precisiones sobre la presencia de restos humanos en contextos fini-pleistocenos, cuestión polémica que afecta a algunos yacimientos del noreste de la Península Ibérica.

\section{LOS RESTOS HUMANOS DE GUILANYÀ E}

Una singularidad señalada al referir el nivel E de Balma Guilanyà es el hallazgo de restos atribuidos a Homo sapiens (Parcerisas et al. 2003; Martínez-Moreno et al. 2006a). Este conjunto recientemente estudiado (Ruiz et al. 2006) se compone de 14 dientes aislados, varios fragmentos de 


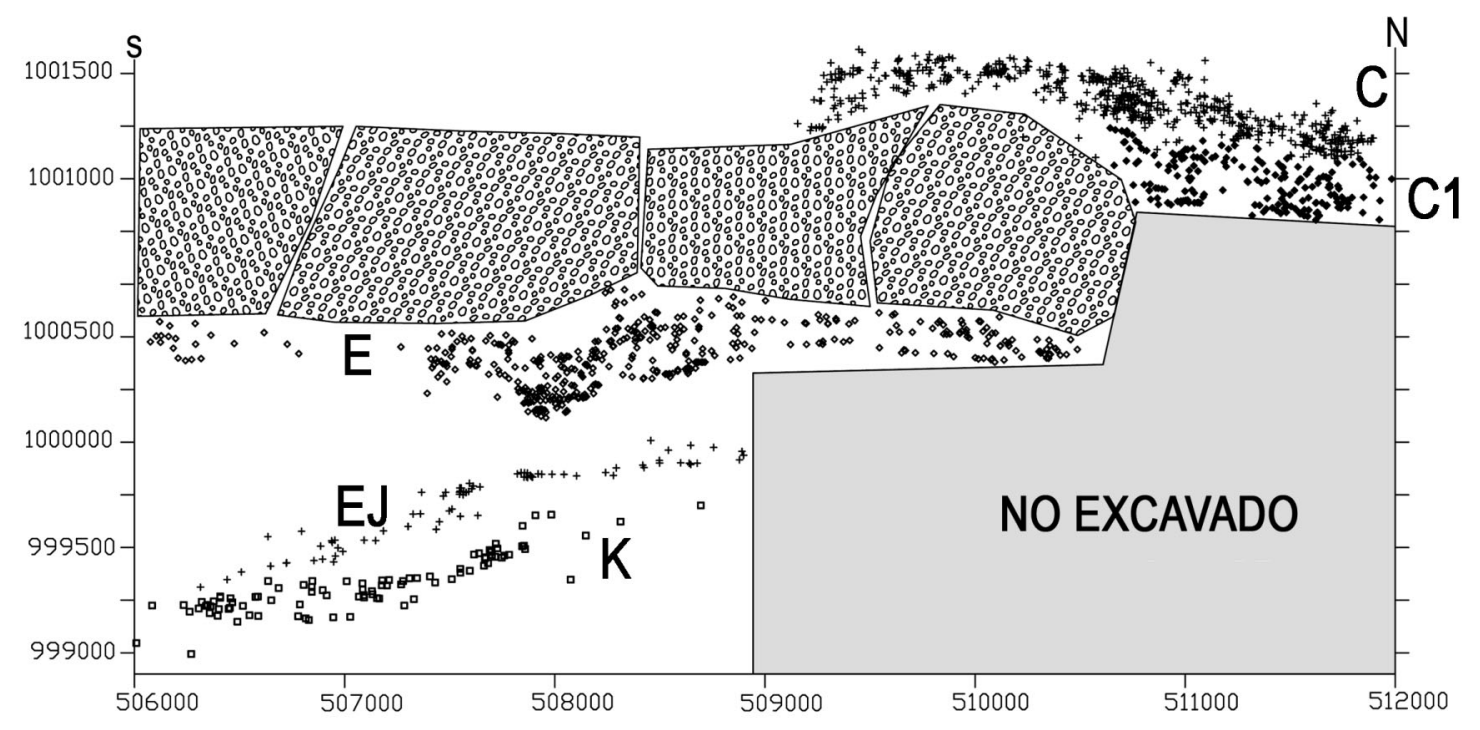

Fig. 2. Dispersión vertical de los diferentes componentes arqueológicos de Guilanyà (compárese con Martínez-Moreno et al., 2006a: 447).

cráneo mal conservados y 5 restos post-craneales ( 3 falanges, 1 escafoides y una diáfisis de radio izquierdo). En base a la duplicación, estadio ontogénico y abrasión dentaria se identifica un infantil de 5 años y dos adultos. El conjunto post-craneal puede atribuirse a un mismo individuo, posiblemente una mujer joven.

Estos restos aparecen dentro de la unidad arqueológica no detectándose ninguna estructura funeraria. Estratigráficamente se localizan por debajo de un gran bloque desprendido de la visera abrigo que sella la secuencia tardiglaciar, siendo improbable que sean intrusivos. Esta cuestión no es secundaria. Los restos humanos adscritos al Paleolítico superior son escasos, y no siempre están exentos de problemas contextuales (Fullola-Pericot y Soler 2004). Así el presunto enterramiento de Roc del Migdia, originariamente atribuido al Tardiglaciar (Estévez et al. 1983), sin embargo proporcionó la fecha $1560 \pm 85 \mathrm{BP}$ (Ua-2550) (Yll et al. 1993) para una falange del inhumado.

En tres restos, que no puede asegurarse que pertenezcan al mismo individuo, se obtuvo el contenido de isótopos estables ${ }^{13} \mathrm{C}$ y ${ }^{15} \mathrm{~N}$, concretamente en la diáfisis de radio, en un fragmento craneal y en un molar superior. La extracción de isótopos del radio (E-1204) se realizó en el Departamento de Ciencias Arqueológicas de la Universidad de Bradford (Reino Unido), mientras el diente (E-3998) y el fragmento craneal (E-NC) fueron tratados en el Laboratorio de Investigaciones Arqueológicas de la Universidad de Estocolmo (Suecia). Sobre las implicaciones que deriva este estudio nos remitimos a García-Guixé et al. (2009). El colágeno óseo recuperado en las muestras E-1204 y E-NC pudo datarse por ${ }^{14} \mathrm{C}$ AMS en el Laboratorio de Uppsala.

\section{MARCO RADIOMÉTRICO Y CONTEXTO CRONO-CLIMÁTICO}

Para realizar atribuciones de orden cronológico hemos defendido la necesidad de transformar las fechas BP en años calendáricos BP (cal BP) tratando la desviación estándar con $2 \sigma$ (Martínez-Moreno et al. 2007). Para la serie de Guilanyà hemos aplicado el modelo de calibración Hulu (Weninger y Jöris 2008). Aunque para el tramo temporal en el que se ubica Guilanyà, este modelo proporciona intervalos cronométricos menos precisos que IntCal04 (Reimer et al. 2004), sin embargo advierte de los bruscos cambios en la concentración de $\mathrm{CO}_{2}$ atmosférico durante el final del Pleistoceno (Hughen et al. 2000). En una línea similar, se ha señalado que no es extraño apreciar significativas asincronías en las tendencias centrales de fechas adscritas al lí- 
mite Pleistoceno/Holoceno, obtenidas a partir de diferentes tipos de muestras de un mismo contexto sedimentario (Bondevik et al. 2006).

Estas observaciones advierten que las oscilaciones de $\mathrm{CO}_{2}$ atmosférico durante el tramo Tardiglaciar/Holoceno antiguo condicionan la calidad del registro radiométrico. Esta reflexión tendría que llamarnos a la prudencia al analizar la cronometría de este período, máxime cuando no son muchas las fechas disponibles y un número significativo de ellas son imprecisas, sin olvidar que en muchos casos no se explicita la relación entre contexto/fecha (Martínez-Moreno et al. 2007).

En este estudio excluimos las dataciones con referencia UBAR-367 y UBAR-368, que aunque no discrepan con el resto de la serie, sus altas desviaciones estándar las convierten en muy imprecisas. Los intervalos calibrados se correlacionan con los rangos de las cronozonas climáticas definidas a partir de la variación del oxígeno $\left({ }^{\delta 18} \mathrm{O}\right)$ que proporciona el modelo GICC05 (Andersen et al. 2006), y que incorpora CalPal 2007 (Weninger et al. 2007) (Tab. 1). Empleamos los límites cronométricos entre cronozonas expuestos en Martínez-Moreno et al. (2007) y para su denominación seguimos indistintamente la propuesta del grupo INTIMATE (Walker et al. 1999) o la seriación palinológica clásica; excepto para el estadio Bolling, al no estar resuelta su correlación con el evento GI-1e o GI-1c $c_{3}$ (ver Weninger et al. 2007).
Ante la ausencia de hogares $u$ otros indicadores que denoten eventos temporales discretos, se seleccionaron muestras que se ajustaran a las concentraciones verticales de los materiales arqueológicos, asumiendo que existe una estrecha relación espacial entre muestra y contexto a datar. No descartábamos que estas asociaciones pudieran verse afectadas por procesos post-deposicionales (migraciones verticales o remociones), sin embargo, estas posibles alteraciones no parecen afectar a la coherencia radiométrica de la serie (Fig. 3).

Las fechas atribuidas a la unidad superior (C1 y C) se adscriben al Holoceno, y confirman la ocupación del abrigo durante el PreBoreal (C1 y C) y Boreal (nivel C). La disrupción cronométrica del nivel $\mathrm{C}$ puede explicarse por el colapso de la visera, que provoca la compresión de esta unidad arqueológica (Casanova et al. 2007). Para la serie holocena se dispone de 2 dataciones sobre muestras de vida corta (cáscara de Corylus), que sugieren unas condiciones climáticas no rigurosas, en paralelo a la expansión del bosque caducifolio en entornos de montaña.

La totalidad de dataciones de la unidad inferior se asignan a la mejora Bolling/Allerod. El nivel E se adscribe a la cronozona GI-1a o Allerod, atribución inferida a partir de muestras sobre carbón, fragmento de Corylus y sobre un diente humano (Ua-34297). Las fechas de EJ y K se integran en la cronozona G1-1e. Al calibrar estas

\begin{tabular}{|c|c|c|c|c|c|c|c|c|c|}
\hline Nivel & Referencia & BP & $\boldsymbol{\sigma}$ & Método & \# & $\delta^{13} \mathrm{C}$ & $\begin{array}{l}\text { cal BP } \\
(95 \%)\end{array}$ & $\begin{array}{c}\text { CRONO- } \\
\text { ZONA }\end{array}$ & $\begin{array}{l}\text { CRONO- } \\
\text { CULTURA }\end{array}$ \\
\hline $\mathrm{K}$ & Beta-247708 & 12310 & 40 & AMS & $\mathrm{C}$ & $-23,9$ & $14850-14090$ & GS-2a/GI-1e & \\
\hline EJ & Beta- 185066 & 12180 & 50 & AMS & $\mathrm{C}$ & $-24,5$ & $14650-13850$ & GI-1e/GI-1d & \\
\hline $\mathrm{E}$ & UBAR-367 & 11460 & 230 & CONV & $\mathrm{C}$ & $-25,7$ & $13810-12890$ & GI-1 $c_{1} /$ GI-1a & \\
\hline E & Beta-247706 & 11110 & 40 & AMS & $\mathrm{C}$ & $-23,6$ & $13110-12910$ & GI-1a & AZILIENSE \\
\hline E-HB & $U a-34297$ & 11095 & 195 & AMS & $\mathrm{CHB}$ & $-19,6$ & $13380-12660$ & GI- $1 c_{1} /$ GI-1a & \\
\hline E & Beta-210729 & 10940 & 50 & AMS & Cor & $-26,4$ & $12990-12710$ & GI-1a & \\
\hline E-HB & $U a-34298$ & 10195 & 255 & AMS & $\mathrm{CHB}$ & $-19,9$ & $12830-10990$ & GI-1a/GS-1/PB & \\
\hline $\mathrm{C} 1$ & Beta-210728 & 9840 & 50 & AMS & Cor & $-25,5$ & $11360-11160$ & PB & \\
\hline $\mathrm{C}$ & Beta- 186168 & 9410 & 60 & AMS & $\mathrm{C}$ & $-21,4$ & $10810-10490$ & PB & \\
\hline $\mathrm{C}$ & UBAR-368 & 8970 & 430 & CONV & $\mathrm{C}$ & $-24,8$ & $11250-9050$ & $\mathrm{~B}$ & MESOLÍTICO \\
\hline $\mathrm{C}$ & Beta- 185064 & 8680 & 50 & AMS & $\mathrm{C}$ & $-26,2$ & $9790-9510$ & B & \\
\hline $\mathrm{C}$ & Beta-210730 & 8640 & 50 & AMS & Cor & $-24,3$ & $9740-9500$ & B & \\
\hline
\end{tabular}

Tab. 1. Cronometría y adscripción a las cronozonas del Tardiglaciar/Holoceno de la serie ${ }^{14} \mathrm{C}$ AMS de Balma Guilanyà a partir del modelo climático GICC05 (Andersen et al. 2006). Los intervalos cronométricos se han obtenido a partir del modelo de calibración Hulu (Weninger y Joris 2008). Las referencias en cursiva indican las fechas inéditas presentadas en este artículo, mientras las consignadas como E-HB corresponden a las dataciones directas sobre restos humanos (ver Garcia-Guixé et al., 2009). El tipo de muestras (\#) datadas son carbón (C), Corylus (Cor) y colágeno de hueso humano (CHB).

T. P., 66, N. ${ }^{\circ}$ 2, julio-diciembre 2009, pp. 45-60, ISSN: 0082-5638

doi: $10.3989 /$ tp.2009.09021 


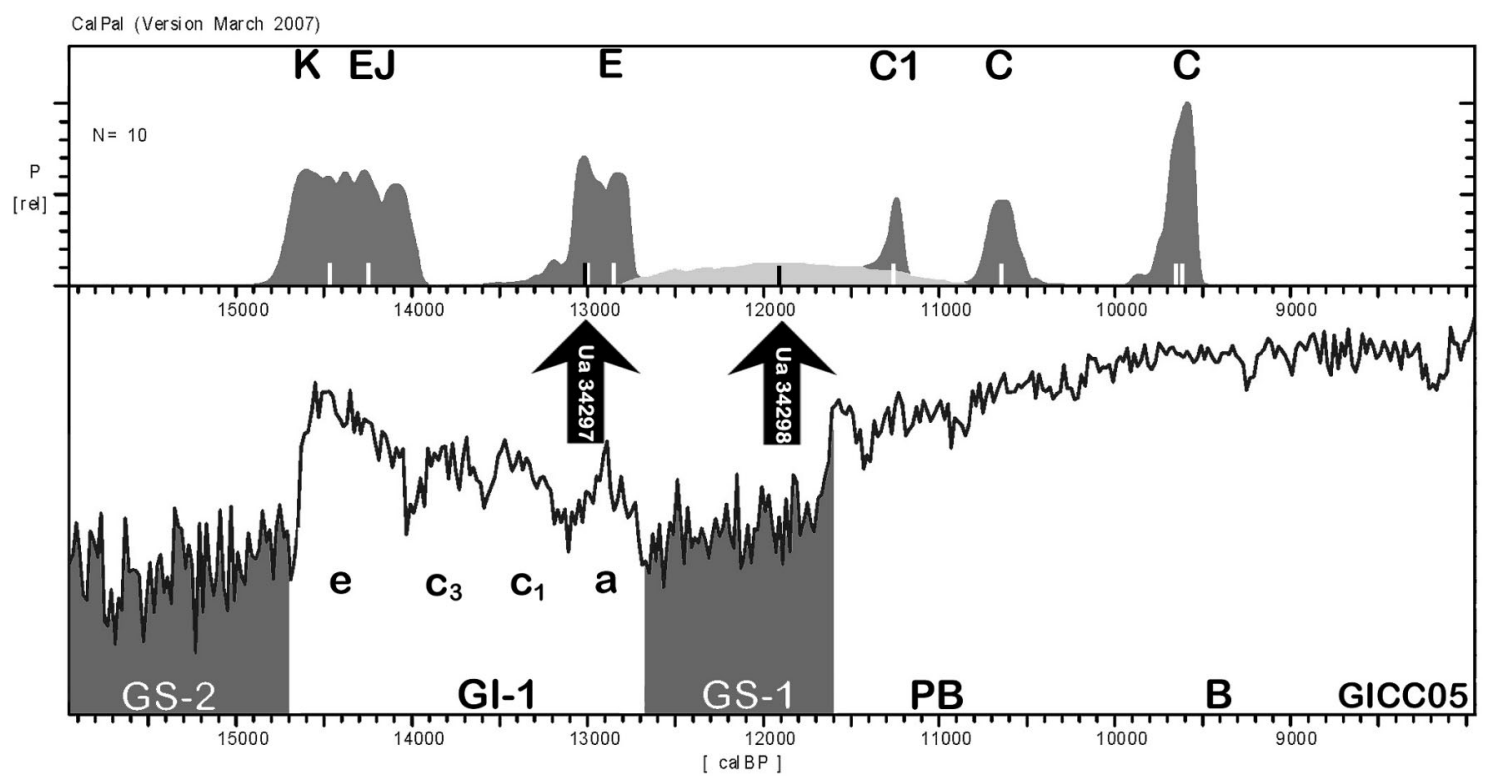

Fig. 3. Modelo cronométrico de Guilanyà. Se indica con flechas la tendencia central de las fechas obtenidas sobre restos humanos.

fechas con desviaciones estándar bajas se generan amplios intervalos cronométricos, que ejemplifican la incidencia de los cambios de concentración de $\mathrm{CO}_{2}$ durante el final del Pleistoceno. Paralelamente, advierten que el inicio de la ocupación de Guilanyà podría retrotraerse al límite Pleniglaciar/Tardiglaciar, posibilidad que enunciamos pero que no retenemos, debido a la posición de sus tendencias centrales.

Los extremos de la distribución de $\mathrm{C} 1$ y $\mathrm{E}$ delimitan un hiato temporal que prácticamente coincide con la duración de la crisis climática del Younger Dryas. En otras ocasiones hemos indicado que la ausencia de ocupación humana durante el GS-1 podría implicar que las fluctuaciones climáticas modulan el ascenso humano a los ecosistemas pirenaicos (Martínez-Moreno et al. 2006a). Sin embargo, esta limitación no queda reflejada en Margineda (Guilaine y Martzluff 2007), asentamiento no muy alejado de Guilanyà. Esta anomalía puede obedecer al escaso conocimiento que disponemos sobre la incidencia de esta crisis climática en los ecosistemas de la vertiente surpirenaica, así como a los pocos asentamientos actualmente conocidos.

Dentro de esta discusión, las dataciones radiométricas Ua-34297 y Ua-34298 se suman a los escasos restos humanos tardiglaciares directamente datados de Europa Occidental (Gar-
cía-Guixé et al. 2009). Aunque sus tendencias centrales señalan una diferencia de más de 1.000 años solares (Fig. 3), esos eventos se ubican en el límite Pleistoceno/Holoceno. La muestra Ua-34297 sitúa este resto humano en el Allerod, adscripción coherente con las fechas Beta-247706, Beta-210729 y UBAR-367. Sin embargo, la tendencia central de Ua-34298 se asocia al GS-1, aunque su amplio recorrido cronométrico se interpola entre el GI-1a/GS-1/PB. Paralelamente, la morfología de la curva gaussiana de esta fecha presenta una baja distribución de probabilidades a lo largo de su recorrido. Estas características nos llevan a considerar que este evento se posiciona en cualquier punto dentro del amplio intervalo temporal señalado por su calibración. La significativa divergencia entre estas tendencias centrales advierte que podrían corresponder a individuos que mueren en momentos distintos, y este desfase temporal quedaría registrado por el radiocarbono. Sin embargo, no descartamos que procesos diagenéticos puedan haber afectado a la calidad del colágeno óseo (García-Guixé et al. 2009).

Si bien estos indicadores señalan tendencias temporales bastante precisas, será necesario obtener nuevas fechas, ya que del marco cronométrico derivan informaciones esenciales para entender el funcionamiento de este yacimiento. 


\section{LOS NIVELES K Y EJ: OBSERVACIONES INICIALES}

Aunque los niveles K y EJ habían sido detectados en campañas anteriores (Martínez-Moreno et al. 2006a), el sondeo practicado en el 2008 sobre una superficie de $9 \mathrm{~m}^{2}$ y con un desarrollo de $2 \mathrm{~m}$ de potencia permitió acceder a estos niveles basales. Sugerimos que estos conjuntos no son el resultado de eventos discretos, sino que al contrario, parecen conformar palimpsestos generados por la visita recurrente al abrigo.

Pese al volumen excavado, el registro lítico recuperado en estas unidades es discreto: entre núcleos, lascas, subproductos de talla y retocados, ascienden a poco más de 220 artefactos en cada conjunto; a los que cabe añadir 20 cantos con indicadores de uso o de talla. Es sintomático el empleo del sílex para confeccionar el instrumental retocado y de los 121 artefactos identificados entre los dos niveles, sólo hay 1 sobre cristal de roca y 2 en caliza. Sin embargo, se aprecia la talla de rocas de aptitud mediocre que aparecen en la visera del abrigo (calizas, rocas metamórficas y cuarzo) representando un no despreciable $15 \%$ del total. La incorporación de rocas locales para complementar el conjunto de soportes, fenómeno detectado en el nivel E (Casanova et al. 2007), denota una incipiente diversificación en la gestión de materias primas en el Tardiglaciar.

No realizaremos una descripción pormenorizada de los atributos morfotécnicos de estos conjuntos, cuestión que será objeto de futuras aportaciones. Sin embargo, algunas tendencias observadas en el componente retocado (el $25-30 \%$ del total) son sugerentes. Los tecnocomplejos $\mathrm{K}$ y EJ se elaboran esencialmente sobre lasca, siendo raros los indicadores de talla laminar. Son comunes los raspadores sobre lascas pequeñas y cortas, inferiores a $3 \mathrm{~cm}$ de longitud. Igualmente, las armaduras se conforman a partir de segmentos de lasca, configurando monopuntas uni y bilaterales (microgravettes), dorsos curvos (puntas azilienses), dorsos triedros espesos y puntas fusiformes (Fig. 4). Algunas presentan fracturas que señalan su posible uso como proyectiles (Philibert 2002).

Excepto los raspadores, el componente adscrito al "fondo común" es escaso, pudiéndose reconocer piezas con borde continuo y retoque simple (raederas) o abrupto (raclettes y truncaturas), piezas esquilladas, denticulados y muescas, elabora-
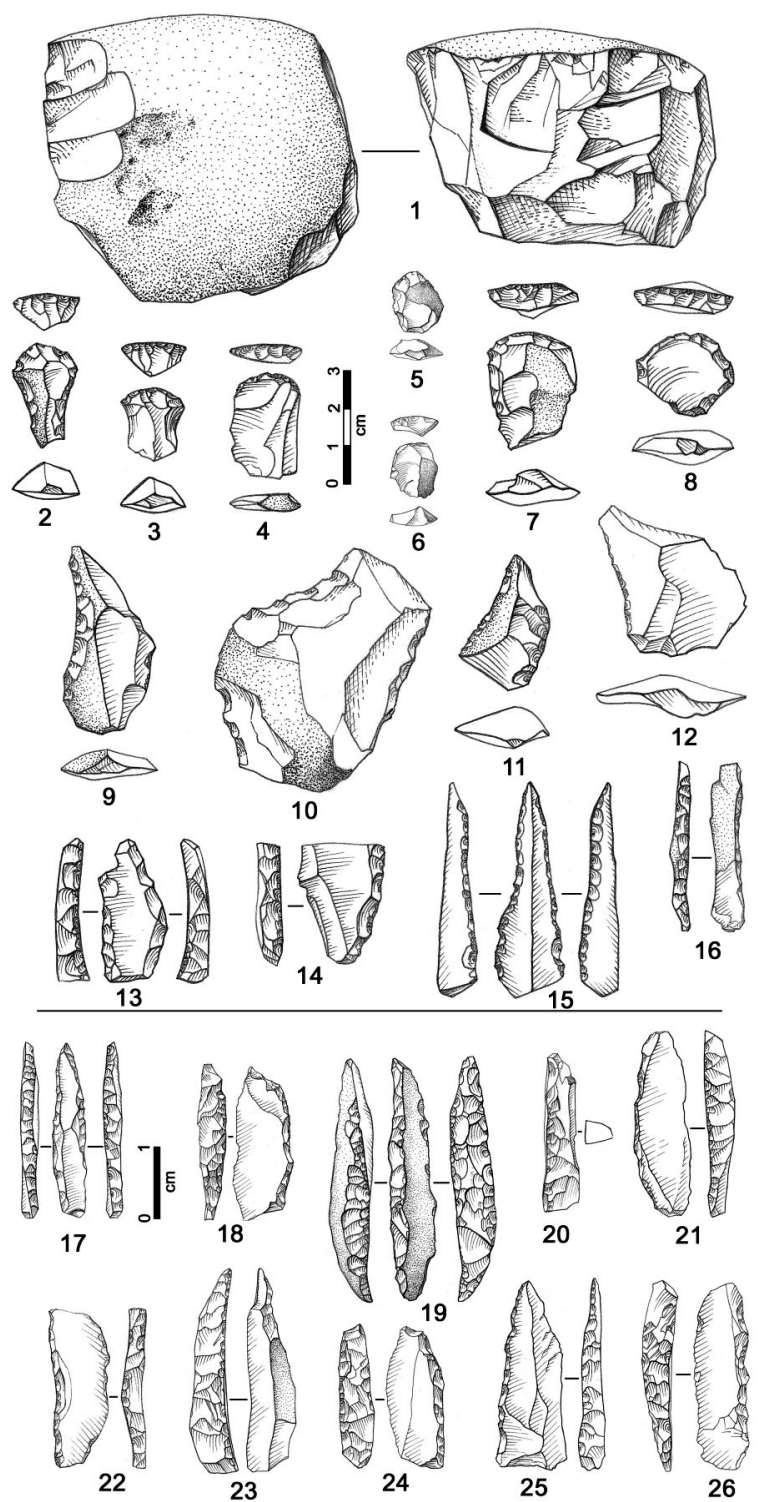

Fig. 4. Artefactos del nivel $\mathrm{K}$ representativos de los tecno-complejos de la secuencia inferior de Guilanyà: 1 núcleo de caliza con cúpulas que denotan su uso como percutor y su posterior talla siguiendo una gestión unipolar (ver Martínez-Moreno et al. 2006b); 2-8 raspadores pequeños y microlíticos sobre lasca; $9,11,12$ raederas y 10 denticulado sobre lasca; $13,14,16$ piezas con retoque abrupto continuo; 15 punta bilateral con retoque abrupto; 17 a 26 dorsos y monopuntas microlíticas elaboradas sobre segmentos o fragmentos de lasca, algunos con fracturas que podrían denotar su uso como proyectiles. Obsérvese la diferencia de escala entre elementos de dorso $(1 \mathrm{~cm})$ y el resto de artefactos (3 cm) (dibujos Mónica López).

dos sobre lasca. En toda la secuencia tardiglaciar se ha recuperado sólo un buril, morfotipo caracte- 
rístico del Magdaleniense (Fullola-Pericot y Soler 2004; Utrilla y Montes 2007).

Aunque entre los 3 conjuntos tardiglaciares se observan elementos comunes como son las monopuntas y raspadores microlíticos, en $\mathrm{K}$ y EJ se aprecia una cierta discontinuidad con lo señalado en el nivel E. Para analizar esta tendencia hemos asociado los retocados en grandes grupos tipológicos para compararlos con los recuperados en los niveles E y C (Casanova et al. 2007) (Tab. 2). Pese a que no son conjuntos numéricamente elevados, y esta tabla tiene sólo un valor orientativo (ya que existen diferencias importantes en las superficies excavadas en los distintos niveles), se intuyen indicadores interesantes.

Desde un punto vista tipológico, se aprecia que la norma que aparece en la cronozona GI-1a y define al nivel $\mathrm{E}$-raspadores y puntas microlíticas(Martínez-Moreno et al. 2006a; Casanova et al. 2007) está presente como mínimo 1.200 años solares antes, en los niveles EJ y K. Paralelamente, se advierten cambios en la composición de los grupos tipológicos, y a medida que avanzamos en el tiempo se aprecia el incremento del instrumental adscrito al "fondo común" en detrimento de los artefactos considerados "especializados". Raederas, muescas y denticulados son cada vez más habituales, mientras que los elementos de dorso se rarifican; siendo especialmente llamativa la ruptura que se registra en el nivel C, en el Boreal. Esta trayectoria, que se ha indicado en los tecno-complejos del Postglaciar del noreste de la Península Ibérica (Martínez-Moreno et al. 2006b, 2007), se inicia en el nivel E, durante el Tardiglaciar. Aunque no disponemos de indicadores definitivos para interpretar su significado, podría denotar cambios en las actividades realizadas en el asentamiento.
El abundante conjunto óseo también proporciona indicaciones interesantes. En general, los restos de fauna están bien conservados, y entre los dos niveles ascienden a más de 800 restos determinables a nivel anatómico y específico. Aunque todavía no se ha cuantificado la composición y diversidad del espectro de fauna en términos de NISP, NME y NMI, sospechamos que estos conjuntos serán relevantes para analizar las estrategias de subsistencia del Tardiglaciar, poco conocidas en el noreste peninsular.

La biodiversidad reconocida es baja. Algunos restos corresponden a pequeños carnívoros -un cánido pequeño (Vulpes vulpes), escasos restos de félidos (Lynx sp.) y un mustélido no determinado-. Entre los ungulados, en K y EJ se detectan restos de Cervus elaphus, y Sus scropha en EJ; especies identificadas en Guilanyà E (Casanova et al. 2007).

Sin embargo, durante el Tardiglaciar la especie más abundante es Capra pyrenaica. Estos conjuntos de fauna pueden calificarse de monoespecíficos, en los que la cabra montesa es la presa principal, y conllevan una serie de implicaciones que hemos mencionado en la introducción de este artículo. Aunque no disponemos de indicadores cuantitativos, pueden señalarse algunos atributos. El primero es la estructura de la población representada por la dentición. Los premolares y molares presentan una elevada atrición, mientras que los dientes que pueden atribuirse a inmaduros no son muy comunes. El hallazgo de varios núcleos óseos identifica la aportación de machos adultos.

El conjunto se compone esencialmente de diáfisis atribuibles a huesos largos con indicadores de actividad antrópica (marcas de corte y de percusión), aunque las termoalteraciones son esca-

\begin{tabular}{|l|r|r|r|r|}
\hline \multicolumn{1}{|c|}{ Grupos tipológicos } & C & E & EJ & K \\
\hline Bordes continuos & 19 & 34 & 9 & 9 \\
Muescas y Denticulados & 35 & 18 & 3 & 5 \\
Truncaduras transversas & - & 2 & 4 & 4 \\
Buriles & - & 1 & - & - \\
Piezas esquilladas & 9 & 4 & 3 & 26 \\
Raspadores & 10 & 27 & 21 & 10 \\
\hline Láminas de dorso & 1 & 13 & 23 & 11 \\
Puntas de dorso & 75 & 122 & 54 & 67 \\
\hline
\end{tabular}

Tab. 2. Evolución de los grupos tipológicos de Balma Guilanyà. 
sas. La repetición de zonas diagnósticas y otros detalles anatómicos señala la aportación de varios individuos, aunque la ausencia de epífisis dificulta realizar estimaciones sobre el NMI. Otras partes anatómicas abundantes son los carpos, tarsos y falanges, mientras que el esqueleto axial está mal representado. Estas observaciones sugieren una introducción selectiva de extremidades a fin de recuperar carne y tuétano. Deberá examinarse si la escasez de esqueleto axial podría indicar un procesado dirigido a su almacenaje y/o transporte, en vistas a un consumo diferido.

Los lagomorfos (Oryctolagus cuniculus), especie identificada en los niveles más recientes, en este sondeo son más abundantes de lo que previamente se había señalado. Será necesario un estudio detallado para determinar si fueron depositados por rapaces o carnívoros terrestres que se instalan en el abrigo, o son el resultado de la aportación humana. Este dato será crítico para analizar la subsistencia humana en el Tardiglaciar (Aura et.al. 2002).

\section{GUILANYÀ Y MARGINEDA: LA ASCENSIÓN A LA MONTAÑA DURANTE EL TARDIGLACIAR}

Pese a que la información que disponemos de los conjuntos óseos y líticos recuperados en el sondeo del 2008 es bastante limitada, permite generar varias hipótesis en relación con la organización de la subsistencia durante el Tardiglaciar en el Pirineo suroriental. Paralelamente, la publicación de la secuencia inferior de Margineda (Guilaine y Martzluff 2007) señala tendencias que podrán evaluarse en Guilanyà; posibilidad que hemos explorado al referir las ocupaciones holocenas de estos yacimientos (Martínez-Moreno et al. 2006c, 2007).

A nuestro entender, la motivación que lleva a que durante el Tardiglaciar se reocupen de forma recurrente entornos de montaña como Guilanyà y Margineda, se relaciona con la adquisición de ungulados rupícolas tal y como concluye el estudio de la fauna de Margineda. Los datos sobre cementocronología dentaria determina que la época de muerte de las cabras se centra al final de verano/inicio de otoño, rango estacional que coincide con el que proporcionan las vértebras de trucha (ver aportaciones de Gardeisen, Martín y LeGall en Guilaine y Martzluff 2007). El hallazgo en
Guilanyà K y EJ de varios bucráneos de cabra montesa sugiere el ataque a grupos de machos, antes de que se reúnan con los rebaños de hembras con crías (generalmente a inicios del otoño).

Para obtener estos recursos, estas gentes se aprovisionan y transportan materias primas con las que confeccionan el instrumental cinegético (piezas de dorso). A este respecto, la norma tecno-tipológica de las unidades inferiores de Margineda no desentona con lo que referimos en los niveles tardiglaciares de Guilanyà. En estos conjuntos calificados como tipológicamente "pobres" de c10, c8 y c7 (Guilaine y Martzluff 2007) abundan monopuntas y raspadores microlíticos estilísticamente muy similares a los de Guilanyà. Por otro lado, estos indicadores tecno-tipológicos no coinciden con lo referido para el filum Magdaleniense del sur de los Pirineos (Fullola-Pericot y Soler 2004; Utrilla y Montes 2007).

Posiblemente, una diferencia significativa deriva de la posición cronométrica en la que estos asentamientos comienzan a ser frecuentados. En otras aportaciones hemos señalado que Margineda c10 se adscribe al GI- $1 c_{3}$, c8 al GI-1c 1 /GI-1a y c7 al GS-1 (Martínez-Moreno et al. 2007), mientras Guilanyà K y EJ se ubican en el GI-1e y el nivel E en el GI-1a (Fig. 5). Aunque la publicación de la serie completa de dataciones tardiglaciares de Margineda (Guilaine y Martzluff 2007) hace necesario revisar estas asignaciones, las fechas disponibles para las ocupaciones inferiores de Guilanyà (K y EJ) son más antiguas que Margineda c10. Pese a esa diferencia temporal, señalamos que en estos asentamientos del Pirineo suroriental, la norma tecno-tipológica compuesta por monopuntas y raspadores microlíticos se visualiza antes del GI-1a.

Un elemento relevante deriva del estudio sobre el origen de las materias primas de los niveles tardiglaciares de Margineda. Lacombe (en Guilaine y Martzluff 2007) determina sílex de diferentes procedencias entre las que cita litologías del entorno del valle del Ebro, como las formaciones silíferas de la Conca de Barberà (Tarragona) y de la Noguera (Lleida), que respectivamente representan distancias de transporte de $120 \mathrm{y}$ 80 km. En Guilanyà reconocemos el tipo "Serra Llarga" procedente de la Noguera (Mangado et al. 2007), y a partir de los atributos morfoscópicos señalados por Lacombe no descartamos que algunas piezas correspondan con lo que él denomina "sílex de Tarragona". Paralelamente, en 
Guilanyà se reconocen otras variedades localizadas en las calizas bioclásticas y laminadas del Prepirineo Oriental (Terradas, 1995; Parcerisas et al. 2003) que podrían corresponder a algunos tipos de sílex presentes en Margineda (observaciones propias). Estas asignaciones, que deberán contrastarse analíticamente, son sugerentes ya que señalan un vector que conecta el valle del Ebro con el macizo pirenaico.

Otro indicador que señala el transporte de materiales exógenos son los escasos -aunque significativos- ornamentos marinos detectados en estos conjuntos. En Margineda c8 aparecen 2 "perlas" tubulares de Dentalium sp.; mientras en c7 se determinan 2 Dentalium enteros, uno roto y otro perforado, 2 Cyclope sp. perforados y un bivalvo con perforación apical. En Guilanyà E se han recuperado 6 "perlas" y 2 Dentalium completos, una Columbella rustica y un Nassarius incrassatus perforados; mientras que en EJ y K contabilizamos dos fragmentos de bivalvo no determinado y 6 Cyclope sp. Aunque establecer su distancia de transporte no es fácil, ya que la evolución batimétrica del Mediterráneo occidental en el Tardiglaciar no está bien precisada, superan los $100 \mathrm{~km}$ de distancia a la costa. En este contexto geográfico, Álvarez-Fernández (1) menciona $C y$ clope sp. en Parco, Cativera y Balma del Gai.

Es interesante el cambio en la selección de ornamentos marinos entre Tardiglaciar/Holoceno, especialmente a partir del Boreal, momento en el que se constata la dispersión de Columbella rusti$c a$ por todo el valle del Ebro (2). Este gasterópodo igualmente aparece en los niveles mesolíticos de Guilanyà y Margineda.

\section{VISUALIZANDO UN "PAISAJE SOCIAL" TARDIGLACIAR EN EL NORESTE DE LA PENÍNSULA IBÉRICA}

En aportaciones anteriores hemos señalado que Guilanyà y Margineda ejemplifican la ascensión recurrente a los ecosistemas de montaña del

(1) E. Álvarez Fernández. 2007: Los objetos de adorno-colgantes del Paleolítico superior y del Mesolítico en la cornisa cantábrica y en el valle del Ebro: una visión europea. Tesis Doctoral inédita. Universidad de Salamanca.

(2) J. Martínez-Moreno, R. Mora y J. Casanova. 2008: "Lost in the mountains?: marine ornaments in the Mesolithic of the northeast of the Iberian Peninsula". En E. Álvarez-Fernández y D. Carvajal (eds.): Not only food. $2^{\text {nd }}$ meeting of the ICAZ Archeomalacology working group-Abstracts: 76.
Pirineo suroriental durante el Bolling/Allerod (Martínez-Moreno et al. 2006a, 2007). Las fechas que presentamos en este artículo confirman esta posibilidad y muestran que Guilanyà comienza a ser frecuentado en el GI-1e. Las "pobres" ocupaciones infrayacentes a c10 de Margineda adscritas al Dryas antiguo, en el Pleniglaciar (Guilaine y Martzluff 1995, 2007), a nuestro entender corresponden con la pulsación GI-1d del ciclo Bolling/Allerod.

Igualmente, sugeríamos que esa ascensión hacia los ecosistemas de montaña debía implicar la articulación de una red de asentamientos durante el final del Pleniglaciar que se localizaría en el contacto entre la periferia del arco surpirenaico y el valle del Ebro, representada por Parco, Forcas I o Chaves. Esta red sostendría el ascenso hacia estadios altitudinales superiores, durante el Bolling/ Allerod (Martínez-Moreno et al. 2006a). Los niveles inferiores de Guilanyà (K y EJ) y Margineda (c10 y c8) permiten evaluar este escenario.

Proponemos que estos conjuntos son el resultado de desplazamientos recurrentes a los valles pirenaicos dirigidos a cazar ungulados rupícolas -especialmente la cabra montesa-; aunque los estudios sobre la ictiofauna y macro-restos vegetales de c8 informan que durante el Allerod esta actividad se complementa con la pesca de Salmo trutta y la recolección de frutos silvestres (ver aportaciones de LeGall y Marinval en Guilaine y Martzluff 2007). En Guilanyà, no descartamos que la recolección de frutos carnosos y secos igualmente comience en esta cronozona (Casanova et al. 2007). Distintos bio-indicadores señalados en Margineda y que posiblemente están presentes en Guilanyà (inferencia que deberá ser demostrada) determinan una ventana estacional precisa -verano/inicio otoño-. El carácter estacional de estos asentamientos identifica un ascenso recurrente a esos entornos de montaña que se prolonga a lo largo del Bolling/Allerod, pero que en Guilanyà parece truncarse durante la pulsación fría del Younger Dryas, mientras que continúa en Margineda (c7 y c6 base) (Guilaine y Martzluff 1995, 2007; Martínez-Moreno et al. 2007).

Un segundo rasgo común son los atributos de la norma tecno-tipológica "empobrecida" - o como preferimos denominar, simplificada- compuesta por monopuntas y raspadores microlíticos de Guilanyà $\mathrm{K}$ y EJ y de Margineda c10 y c8. Estos conjuntos líticos muestran una marcada tendencia que puede relacionarse con una reducida o -si se pre- 
fiere- una especializada gama de actividades, relacionadas con la adquisición y procesado de ungulados de montaña. Sin embargo, el incremento del "fondo común" que se intuye en Guilanyà E permite inferir una mayor diversidad tecno-tipológica que interpretamos como un indicador de la ampliación de las actividades realizadas en el asentamiento (Casanova et al. 2007). Este cambio en el uso del asentamiento, de ocupaciones especializadas hacia otras de carácter residencial, es un escenario no muy distinto al propuesto para Margineda por Phillibert (2002).

Sintomáticamente, en otras zonas del noreste peninsular se reconocen conjuntos con indi- cadores tipológicos similares a los señalados en el área surpirenaica. Varios estudios recientes señalan la existencia de cambios en los conjuntos líticos post-magdalenienses, generalmente atribuidos al Epipapeolítico microlaminar (GarcíaArgüelles et al. 2005), aunque igualmente se sugiere su adscripción al Magdaleniense superior final (García Catalán 2007). Para establecer su posición crono-cultural es central el registro radiométrico que proporcionan los yacimientos de Molí del Salt, Balma del Gai, Cativera, Parco, Filador, Font Voltada, Vidre, Picamoixons (entre otros), entre el XIII-XI milenio BP no calibrado (Tab. 3).

\begin{tabular}{|c|c|c|c|c|c|c|c|}
\hline Yacimiento & Nivel & Referencia & BP & $\sigma$ & Método & \# & cal BP $(95 \%)$ \\
\hline Guilanyà & $\begin{array}{c}\text { K } \\
\text { EJ } \\
E \\
\text { E-HB } \\
\text { E }\end{array}$ & $\begin{array}{c}\text { Beta- } 247708 \\
\text { Beta- } 185066 \\
\text { Beta-247706 } \\
\text { Ua-34297 } \\
\text { Beta-210729 }\end{array}$ & $\begin{array}{l}12310 \\
12180 \\
11110 \\
11095 \\
10940\end{array}$ & $\begin{array}{r}40 \\
50 \\
40 \\
195 \\
50\end{array}$ & $\begin{array}{l}\text { AMS } \\
\text { AMS } \\
\text { AMS } \\
\text { AMS } \\
\text { AMS }\end{array}$ & $\begin{array}{c}\mathrm{C} \\
\mathrm{C} \\
\mathrm{C} \\
\mathrm{CHB} \\
\text { Cor }\end{array}$ & $\begin{array}{l}14850-14090 \\
14650-13850 \\
13110-12910 \\
13380-12660 \\
12990-12710\end{array}$ \\
\hline Margineda & $\begin{array}{l}\text { c10 } \\
\text { c10 } \\
\text { c8 sup } \\
\text { c8 } \\
\text { c7 }\end{array}$ & $\begin{array}{l}\text { Ly-4898 } \\
\text { Ly-4896 } \\
\text { Ly-4407 } \\
\text { Ly-5418 } \\
\text { Ly-4403 }\end{array}$ & $\begin{array}{l}11870 \\
11690 \\
11320 \\
11230 \\
10340\end{array}$ & $\begin{array}{r}110 \\
90 \\
120 \\
170 \\
130\end{array}$ & $\begin{array}{l}\text { CONV } \\
\text { CONV } \\
\text { CONV } \\
\text { CONV } \\
\text { CONV }\end{array}$ & $\begin{array}{l}\mathrm{C} \\
\mathrm{C} \\
\mathrm{C} \\
\mathrm{C} \\
\mathrm{C}\end{array}$ & $\begin{array}{l}14030-13510 \\
13820-13340 \\
13460-12980 \\
13470-12790 \\
12760-11640\end{array}$ \\
\hline Parco & $\begin{array}{l}\text { cueva-Ic } \\
\text { cueva-Ic } \\
\text { cueva-Ib } \\
\text { exterior-I }\end{array}$ & $\begin{array}{c}? \\
\text { OxA-8657 } \\
\text { OxA-8656 } \\
\text { Gak-14102 }\end{array}$ & $\begin{array}{l}12605 \\
11270 \\
11430 \\
11510\end{array}$ & $\begin{array}{r}60 \\
90 \\
60 \\
170\end{array}$ & $\begin{array}{c}\text { AMS } \\
\text { AMS } \\
\text { AMS } \\
\text { CONV }\end{array}$ & $\begin{array}{l}\mathrm{C} \\
\mathrm{C} \\
\mathrm{C} \\
\mathrm{C}\end{array}$ & $\begin{array}{l}15320-14840 \\
13350-12990 \\
13470-13190 \\
13720-13080\end{array}$ \\
\hline Molí del Salt & $\begin{array}{c}\text { B1 } \\
\text { B1 } \\
\text { Asup } \\
\text { Asup }\end{array}$ & $\begin{array}{c}\text { GifA-101038 } \\
\text { GifA-101037 } \\
\text { Beta-17598 } \\
\text { Beta-17599 }\end{array}$ & $\begin{array}{l}12510 \\
11940 \\
10990 \\
10840\end{array}$ & $\begin{array}{r}100 \\
100 \\
50 \\
50\end{array}$ & $\begin{array}{l}\text { AMS } \\
\text { AMS } \\
\text { AMS } \\
\text { AMS }\end{array}$ & $\begin{array}{l}\mathrm{C} \\
\mathrm{C} \\
\mathrm{C} \\
\mathrm{C}\end{array}$ & $\begin{array}{l}15300-14540 \\
14070-13590 \\
13050-12730 \\
12890-12690\end{array}$ \\
\hline Picamoixons & IIB & AA 5810 & 11055 & 90 & AMS & $\mathrm{C}$ & $13150-12750$ \\
\hline Font Voltada & & UBAR 72 & 10920 & 240 & CONV & $\mathrm{C}$ & $13290-12450$ \\
\hline Cativera & $\begin{array}{l}\mathrm{Cb} 3 \\
\mathrm{C} 3 \\
\mathrm{C} 2\end{array}$ & $\begin{array}{l}\text { AA } 23372 \\
\text { AA } 23371 \\
\text { AA } 23370\end{array}$ & $\begin{array}{l}11135 \\
11230 \\
10660\end{array}$ & $\begin{array}{r}80 \\
100 \\
120\end{array}$ & $\begin{array}{l}\text { AMS } \\
\text { AMS } \\
\text { AMS }\end{array}$ & $\begin{array}{l}\mathrm{C} \\
\mathrm{C} \\
\mathrm{C}\end{array}$ & $\begin{array}{l}13260-12820 \\
13330-12930 \\
12880-12280\end{array}$ \\
\hline Filador & $\begin{array}{l}8 / 9 \\
8 / 9\end{array}$ & $\begin{array}{l}\text { OxA-8660 } \\
\text { OxA-8659 }\end{array}$ & $\begin{array}{l}11000 \\
10864\end{array}$ & $\begin{array}{l}55 \\
60\end{array}$ & $\begin{array}{l}\text { AMS } \\
\text { AMS }\end{array}$ & $\begin{array}{l}\mathrm{C} \\
\mathrm{C}\end{array}$ & $\begin{array}{l}13080-12720 \\
12930-12690\end{array}$ \\
\hline Gai & $\begin{array}{c}\text { II } \\
\text { base }\end{array}$ & $\begin{array}{l}\text { Gif-95630 } \\
\text { Gif- } 10029\end{array}$ & $\begin{array}{l}12240 \\
11170\end{array}$ & $\begin{array}{l}110 \\
160\end{array}$ & $\begin{array}{l}\text { CONV } \\
\text { CONV }\end{array}$ & $\begin{array}{l}\mathrm{C} \\
\mathrm{C}\end{array}$ & $\begin{array}{l}14900-13820 \\
13380-12740\end{array}$ \\
\hline
\end{tabular}

Tab. 3. Calibración de las fechas atribuidas al Epipaleolítico microlaminar mediterráneo (sg. García-Argüelles et al. 2005). La serie de Margineda procede de Martínez et al. (2006c, 2007). 
Aunque no es nuestro interés entablar una discusión de orden crono-cultural, al referir estos yacimientos del noreste peninsular, varios detalles nos llaman la atención. Para su discusión, García-Argüelles et al. (2005) compartimenta artificialmente las fechas de Balma del Gai II, Molí del Salt B1 y Asup, Font Voltada, Filador 8/9, Picamoixons, Cativera c3 y c2 o Parco-cueva IB, en función de si su tendencia central se posiciona en el XII o en el XI milenio BP. Igualmente, la comparación directa de fechas $\mathrm{BP}$ en los términos que propone García Catalá (2007) tampoco clarifica esta situación.

Como alternativa proponemos calibrar estas fechas, incorporando las que proporcionan los yacimientos surpirenaicos discutidos en este artículo, aplicando la misma sistemática antes expuesta al referir la serie radiométrica de Guilanyà.

Este proceder permite visualizar que los intervalos cronométricos calibrados señalan una importante recurrencia temporal en torno a la cronozona Allerod (Fig. 5).

Los conjuntos líticos recuperados en estos contextos se caracterizan por la presencia de monopuntas, raspadores microlíticos y escasos buriles, tendencia que según García Catalán (2007) se reconoce en Asup de Molí del Salt, Filador 8/9, Font Voltada, Picamoixons, Cativera c3 y c2, Parco Ib y Ic, Balma del Gai-base. Consideramos que estos indicadores tipológicos no difieren de lo que hemos referido para los conjuntos tardiglaciares de Guilanyà y Margineda, y que asignamos al Aziliense.

Aunque sus rangos cronométricos se centran en el GI-1a, hemos indicado que en los yacimientos pirenaicos esta norma tipológica se inicia con anterioridad -en el GI-1e- pudiendo retrotraerse al límite GS-2a/GI-1e. En la figura 5 se indican varias fechas "anómalas" dentro de esa tendencia centralizada en torno al Allerod, como, por ejemplo, la datación de Parco-cueva Ic $12605 \pm 60$ BP para la que no se dispone de más precisiones (García Argüelles et al. 2005), o GifA-101038 del nivel B1 de Molí del Salt. Estos contextos, en los que asumimos que presentan características tipológicas similares, disponen de fechas con significativas diferencias en sus tendencias centrales. Igualmente, debería precisarse el significado de la inversión cronométrica entre Gif-95630 del nivel II de Balma del Gai atribuida al GI-1e, en consecuencia más antigua que Gif-100291 adscrita al GI-1a y que corresponde con la base de la secuencia arqueológica (Allué et al. 2007). Sería interesante determinar las causas de esas discontinuidades radiométricas, ya que podrían sugerir que esta tradición se inicia al final del Pleniglaciar, tal y como parece intuirse en Guilanyà $\mathrm{K}$.

Otro detalle es que los yacimientos adscritos a la cronozona Allerod - como Font Voltada (Mir y Freixas 1993), Filador (García-Argüelles et al. 2005), Cativera, Picamoixons y Molí del Salt (Vaquero (ed.) 2004; García Catalán 2007)- están estrechamente vinculados con los afloramientos de sílex de la Conca de Barberá, mientras Parco (Mangado et al. 2007) y Cova Gran de Santa Linya (Martínez-Moreno et al. 2008) se relacionan con los depósitos de materia prima detectados en la Noguera. Hemos indicado que, según Lacombe, algunos de estos tipos de sílex aparecen en Margineda, y en Guilanyà registramos materiales de la Noguera. De confirmarse estas atribuciones, sea cual sea su importancia dentro de estos conjuntos, son identificadores físicos que definen una conexión geográfica de alcance regional. Igualmente, los ornamentos marinos (Cyclope, Columbella y Dentalium) recuperados en los enclaves de montaña señalan un nexo preciso con el litoral mediterráneo.

La convergencia de atributos como son el transporte/circulación de materias primas y gasterópodos marinos alóctonos, así como la formalización de una norma tecno-tipológica común (aunque puede presentar cierta polimorfía interna) en un rango cronométrico similar, podría señalizar la construcción de una incipiente red social. Estas recurrencias, que se visualizan especialmente durante el Allerod, conectan un significativo número de asentamientos del Bajo Ebro y el arco externo surpirenaico con estos enclaves de montaña (Fig. 6). No descartamos que este ámbito de relación tenga una extensión geográfica más amplia, pudiendo seguirse por la Depresión central catalana -nivel II de Balma del Gai (Allué et al. 2007)-, el Prepirineo de Huesca -nivel 1c de Chaves, niveles 11 y 10 de Forcas I- (Utrilla y Montes 2007) o en el extremo septentrional del Sistema Ibérico -el nivel I de Cova Matutano(Olaria 1999). Igualmente, será necesario analizar su posible articulación con la vertiente norpirenaica (Barbaza y Lacombe 2005) o la cornisa cantábrica (Fernández-Tresguerres 2006), regiones en las que el Aziliense se considera una tradición cultural clásica. 


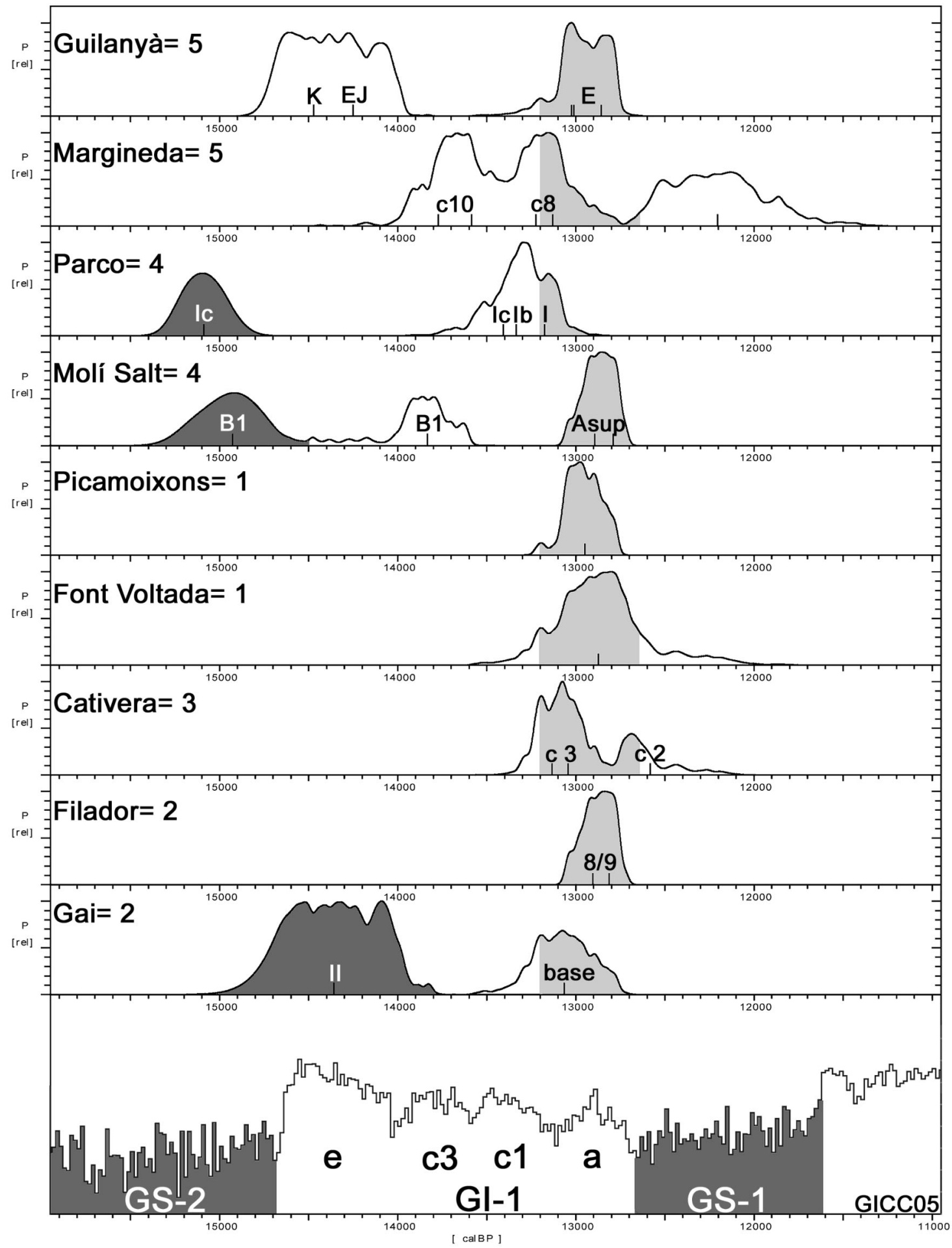

Fig. 5. Cuadro cronométrico de los conjuntos del Bajo Ebro y el sureste del Pirineo. En gris claro se posiciona el intervalo temporal del estadio GI-1a (Allerod) sobre la distribución cronométrica de las fechas. En gris oscuro se señalan discontinuidades radiométricas en el mismo contexto arqueológico de Parco Ic y Molí del Salt B1, y se indica la inversión estratigráfica señalada por la fecha más antigua de Gai. 


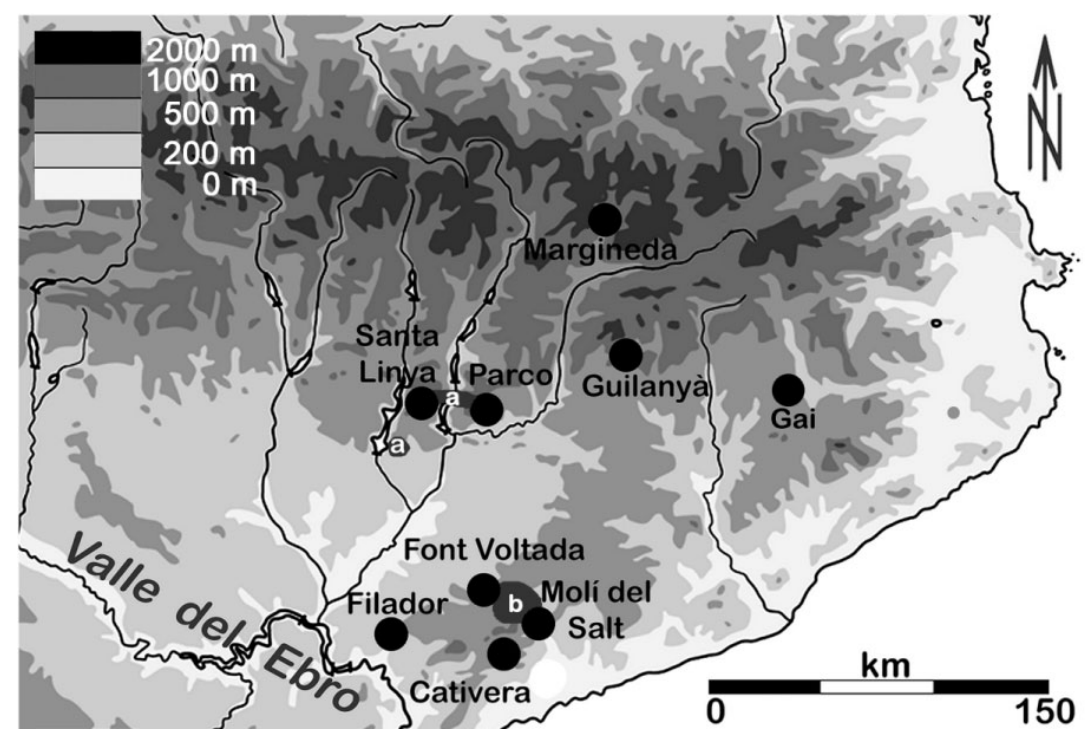

Fig. 6. Localización de los yacimientos del Epipaleolítico microlaminar mediterráneo del bajo Ebro y del sureste de los Pirineos. Se posicionan los afloramientos silíferos de la Noguera (a) y de la Conca de Barbera (b).

\section{PERSPECTIVAS DE FUTURO: EL SIGNIFICADO DE LA NORMA "AZILIENSE"}

Los conjuntos $\mathrm{K}$ y EJ de Guilanyà derivan varias cuestiones que afectan a la caracterización de los cazadores-recolectores del Tardiglaciar del nordeste de la Península Ibérica. Estas observaciones iniciales diseñan varias líneas de investigación entre las que subrayamos: a) las implicaciones relatadas con la gestión recurrente de los entornos de montaña a partir de la mejora Bolling/Allerod; b) el significado de la norma tecno-tipológica detectada en las secuencias inferiores de Guilanyà y Margineda; c) su posible extensión espacio-temporal por la periferia superinaica; d) la articulación de un "paisaje social" en el noreste peninsular durante el Tardiglaciar.

En función que avance el estudio del registro arqueológico de Guilanyà, esperamos responder a las cuestiones que hemos enunciado de forma esquemática en este artículo.

Consideramos que la norma compuesta por monopuntas y raspadores microlíticos definen una tradición clásica en los Pirineos: el Aziliense (Martínez-Moreno et al. 2006a, 2007). Las concomitancias de Guilanyà $\mathrm{K}$ y EJ con Margineda c10 y c8 justifican que a esta adscripción, a tenor de su posición cronométrica, deba añadírsele el calificativo "antiguo". Como tradición cultural se iniciaría con anterioridad al GI-1a, durante las cronozonas GI-1e y GI-1 $c_{3}$. Durante el Allerod se sigue por un amplio rango geográfico que abarca el noreste de la Península Ibérica, y que habitualmente se ha denominado Epipaleolítico microlaminar. Esta tradición crono-cultural, definida por Fortea (1973), designa los conjuntos líticos postmagdalenienses. Sin embargo, coincidimos con Cava (2004) cuando afirma que los atributos que señalan esta adscripción cultural merecen ser revisados.

Igualmente, para esta tendencia tecno-tipológica de la cronozona GI-1a no nos parece apropiada la atribución Magdaleniense superior final. Los conjuntos líticos del Tardiglaciar de Guilanyà y Margineda no tienen un encaje directo con los indicadores tecno-tipológicos que caracterizan la tradición Magdaleniense. Esta posición fue advertida al referir la "transición" Magdaleniense/Aziliense en los yacimientos clásicos de la vertiente norpirenaica (la Vache, Rhodes II, la Tourrasse o Rive Gauche de Mas d'Azil) en los que se señala una significativa ruptura tipológica (Simonnet 1976).

Esta perspectiva nos sugiere la necesidad de realizar estudios detallados dirigidos a analizar los sistemas técnicos del Pleniglaciar y del Bo- 
lling/Allerod. Más que representar dos tradiciones filéticas interconectadas, sospechamos que podrían esconder una significativa discontinuidad tecno-tipológica, subsistencial -y posiblementesocial, en la trayectoria de los cazadores-recolectores del límite Pleistoceno/Holoceno. En relación a esta cuestión, la nueva secuencia arqueológica detectada en Cova Gran de Santa Linya (Martínez-Moreno et al. 2008) podría aportar indicadores con los que caracterizar las transformaciones tecno-tipológicas que se suceden entre Magdaleniense y post-Magdaleniense.

Los incipientes indicadores reconocidos en Guilanyà podrían confirmar que la construcción de un "paisaje social" en el noreste peninsular se consolida durante el Tardiglaciar, posibilidad señalada tentativamente en aportaciones previas (Martínez-Moreno et al. 2006b, 2007). Será necesario examinar si esta red de interacción social articulada en torno al valle del Ebro puede retrotraerse al Pleniglaciar (Utrilla y Mazo 1996; Utrilla y Montés 2007).

En resumen, las observaciones preliminares derivadas del sondeo realizado en Guilanyà nos hacen sospechar que estos pequeños asentamientos "perdidos" en la montaña, esconden informaciones esenciales para reconstruir las estrategias de subsistencia y la organización social de los cazadores-recolectores del Noreste de la Península Ibérica entre el final del Pleistoceno y el Holoceno antiguo.

\section{AGRADECIMIENTOS}

Los comentarios realizados por dos revisores anónimos han mejorado la comprensión de este artículo. Michel Martzluff ha compartido con nosotros sus amplios conocimientos sobre el Aziliense pirenaico. Obvia señalar que somos los únicos responsables de cualquier error u omisión que se aprecie en este artículo.

Desde 1992, la familia Guilanyà nos permite realizar trabajos de excavación, que son financiados por el Servei d'Arqueología i PaleontologíaGeneralitat de Catalunya y el Institut d'Estudis Ilerdencs-Diputació de Lleida. Estos resultados se integran dentro del proyecto Asentamiento humano en el Pirineo Oriental durante el Pleistoceno Superior y el Holoceno, reconocido por el Ministerio de Educación y Ciencia (HUM200760317/HIST). Ésta es una publicación del gru- po Cultura material i comportament humà, reconocido por el Vice-rectorat d'Investigació de la Universitat Autònoma de Barcelona y AGAUR (2005SGR-00057). Por imperativo administrativo se menciona el apoyo marginal de esta agencia en el programa EXCAVA2006.

\section{BIBLIOGRAFÍA}

Allué, E.; Nadal, J.; Estrada, E. y García-Argüelles, P. 2007: "Los datos antracológicos de la Balma del Gai (Bages, Barcelona): una aportación al conocimiento de la vegetación y la explotación de los recursos forestales durante el Tardiglaciar en el NE peninsular". Trabajos de Prehistoria 64, 1: 87-97.

Andersen, K.; Svensson, A.; Johnsen, S.; Rasmussen, S.; Bigler, M.; Röthlisberger, R.; Ruth, U.; Siggaard, M.; Peder, J.; Dahl, D.; Vinther, B. y Clausen, H. 2006: "The Greenland Ice Core Chronology 2005, 15-42 ka. Part 1: constructing the time scale". Quaternary Science Reviews 25: 3258-3267.

Aura, J.E.; Villaverde, V.; Pérez, M.; Martínez, R. y Guillem, P. 2002: "Big game and small prey: Paleolithic and Epipaleolithic economy from Valencia (Spain)". Journal of Archaeological Method and Theory 9: 215-268.

Barbaza, M. y Lacombe, S. 2005: “L'azilien pyrénéen: une culture originale?". En: J. Jaubert y M. Barbaza (eds.): Territoires, déplacementes, mobilité, échanges durant la préhistoire. CTHS. París: 421-427.

Bondevik, S.; Mangerud, J.; Birks, H.; Gulliksen, S. y Reimer, S. 2006: "Changes in North Atlantic radiocarbon reservoir ages during the Allerod and Younger Dyas". Science 312: 1514-1517.

Casanova, J.; Martínez-Moreno, J. y Mora, R. 2007: "Traçant l'ocupació dels Pirineus: Balma Guilanyà i els caçadors-recol.lectors del Tardiglacial i l'Holocé antic al Prepirineu Oriental'. Tribuna d'Arqueologia 2006: 59-83.

Cava, A. 2004: “Los 'procesos culturales' del comienzo del Holoceno en la Cuenca del Ebro y su contextualización". Saldvie 4: 17-40.

Estévez, J.; Vila, A. e Y11, E. 1983: "Réflexions sur la dynamique économique et industrielle dans le nord du Levant ibérique (16.000-7.000 BP)". Rivista di Scienze Preistoriche XXXVIII: 9-19.

Fernández-Tresguerres, J. A. 2006: "El Aziliense de la región cantábrica”. Zephyrus LIX: 163-179.

Fortea, J. 1973: Los complejos microlaminares y geométricos del Epipaleolítico mediterráneo español. Universidad de Salamanca. Salamanca.

Fullola-Pericot, J.M. y Soler, N. 2004: "El Paleolític superior a Catalunya". Fonaments 10-11: 97-132. 
Gamble, C. 1993: Timewalkers. The prehistory of global colonization. Penguin. Londres.

García-Argüelles, P.; Nadal, J. y Fullola-Pericot, J.M. 2005: "El Abrigo del Filador (Margalef de Montsant, Tarragona) y su contextualización cultural y cronológica en el Nordeste Peninsular". Trabajos de Prehistoria 62, 1: 65-83.

García Catalán, S. 2007: "La industria lítica del nivel Asup del Molí del Salt (Vimbodí, Tarragona) y su contextualización en el Paleolítico Superior final de la vertiente mediterránea de la Península Ibérica". Trabajos de Prehistoria 64, 2: 157-168.

García-Guixé, E.; Martínez-Moreno, J.; Mora, R., Núñez, M. y Richards, M.P. 2009: "Human and animal stable isotope analysis from late Upper Palaeolithic site of Balma Guilanyà, Southeastern PrePyrenees, Spain". Journal of Archaeological Science 36: 1018-1026.

Guilaine, J. y Martzluff, M. 1995: Les excavacions a la Balma de la Margineda (1979-1991) I-III. Ministeri d'Afers Socials i Cultura. Andorra.

Guilaine, J. y Martzluff, M. 2007: Les excavacions a la Balma de la Margineda (1979-1991) IV. Ministeri d'Afers Socials i Cultura. Andorra.

Hughen, K.; Southon, J.; Lehman, S. y Overpeck, J. 2000: "Synchronous radiocarbon and climate shifts during the last deglaciation". Science 290, 19511954.

Mangado, X.; Mercadal, O.; Fullola-Pericot, J.M.; Esteve, X.; Langlais, M.; Nadal, J., Estrada, A. y Bergadà, M. 2006: "Montlleó (La Cerdanya, Lleida), un yacimiento Magdaleniense de alta montaña al aire libre en los Pirineos catalanes". O Paleolítico. IV Congresso de Arqueología Peninsular (Faro 2004): 471-480.

Mangado, X.; Petit, M.A.; Fullola-Pericot, J.M. y Bartrolí, R. 2007: "El paleolític superior final de la cova del Parco (Alòs de Balaguer, la Noguera)". Revista d'Arqueología de Ponent 16-17: 45-62.

Martínez-Moreno, J.; Mora, R. y Casanova, J. 2006a: "Balma Guilanyà y la ocupación de la vertiente sur del Prepirineo del Noreste de la Península Ibérica durante el Tardiglaciar". En J. Sanchidrián, A. M. ${ }^{\text {a }}$ Márquez y J. M. ${ }^{\text {a }}$ Fullola (eds.): La cuenca mediterránea durante el Paleolítico Superior. IV Simposio de Prehistoria Cueva de Nerja, 444-457. Nerja.

Martínez-Moreno, J.; Mora, R. y Casanova, J. 2006b: "El Mesolítico de los Pirineos surorientales: una reflexión sobre el significado de las 'facies de fortuna' del Postglaciar". En A. Alday (coord.): El Mesolítico de muescas y denticulados en la cuenca del Ebro y el litoral mediterráneo peninsular. Memorias de Yacimientos Alaveses 11. Gasteiz: 163-192.

Martínez-Moreno, J.; Martzluff, M.; Mora, R. y Guilaine, J. 2006c: 'D'une pierre deux coups: entre percussion posée et plurifonctionnalité. Les poids des comportements 'opportunistes' dans l'Epipa-
léolithique-Mésolithique pyrénéen”. En L. Astruc, F. Bon, V. Léa, P.-Y. Milcent y S. Philibest (eds.): Normes techniques et practiques sociales. De la simplicité des outillages Pré et Protohistoriques. CEPAM. Antibes: 147-160.

Martínez-Moreno, J.; Mora, R. y Casanova, J. 2007: "El contexto cronométrico y tecno-tipológico durante el Tardiglaciar y Postglaciar de la vertiente sur". Revista d'Arqueologia de Ponent 16-17: $7-44$.

Martínez-Moreno, J.; Mora Torcal, R. y Torre, I. de la 2008: "La Cova Gran de Santa Linya i el poblament humà del vessant sud dels Pirineus al Plistocé superior i a l'Holocè'. Tribuna d'Arqueologia 2007: 69-92.

Mir, A. y Freixas, A. 1993: "La Font Voltada, un yacimiento de finales de Paleolítico superior en Montbrió de la Marca". Cypsela X: 13-21.

Olaria, C. 1999: Cova Matutano (Vilafamés, Castellón). Un modelo ocupacional del magdaleniense superior-final en la vertiente mediterránea peninsular. Monografias de Prehistòria i Arqueologia Castellonenques 5. Castelló.

Parcerisas, J.; Mora, R.; Pallarés, M. y Martínez-Moreno, J. 2003: "Balma Guilanyà (Navès, Solsonès)". En Jornades d'Arqueologia i Paleontologia-2000. Comarques de Lleida (Lleida 2000), 73-90. Barcelona.

Philibert, S. 2002: Les derniers “sauvages”. Territoires économiques et systèmes techno-fonctionnels mésolithiques. BAR Int. Series 1969. Archaeopress. Oxford.

Reimer, P.; Baillie, M.; Bard, E.; Bayliss, A.; Beck, J.; Bertrand, C.; Blackwell, P.; Buck, C.; Burr, G.; Cutler, K.; Damon, P.; Edwards, L.; Fairbanks, R.; Friedrich, M.; Guilderson, T.; Hogg, A.; Hughen, K.; Kromer, B.; McCormac, G.; Manning, S.; Ramsey, C.B.; Southon, J.; Stuiver, M.; Talamo, S.; Taylor, F.; Van der Plicht, J. y Weyhenmeyer, C. 2004: "IntCal04 Terrestrial radiocarbon age calibration, 0-26 Cal Kyr BP". Radiocarbon 46: 1029-1058.

Ruiz, J.; García-Sívoli, C.; Martínez-Moreno, J. y Subirà, M.E. 2006: "Los restos humanos del Tardiglaciar de Balma Guilanyà". En J. Sanchidrián, A. M. ${ }^{a}$ Márquez y J. M. ${ }^{a}$ Fullola (eds.): La cuenca mediterránea durante el Paleolítico Superior. IV Simposio de Prehistoria Cueva de Nerja, 458-467. Nerja.

Simonnet, R. 1976: “Les civilizations de 1'Epipaléolithique et du Mésolithique dans les confins pyrénnéens de la Gascogne et Languedoc". En H. de Lumley (ed.): La Prehistoire Française. CNRS. Paris: 1412-1419.

Straus, L.G. 1987: "Upper paleolithic ibex hunting in southwest Europe". Journal of Archaeological Science 14: 63-178.

T. P., 66, N. ${ }^{\circ}$ 2, julio-diciembre 2009, pp. 45-60, ISSN: 0082-5638 doi: $10.3989 /$ tp.2009.09021 
Terradas, X. 1995: Las estrategias de gestión de los recursos líticos del Prepirineo catalán en el IX milenio BP: el asentamiento prehistórico de la Font del Rós. Treballs d'Arqueologia 3. Bellaterra.

Utrilla, P. y Mazo, C. 1996: "Le paléolithique supérieur dans le versant sud des Pyrénées, communications et influences avec le monde pyrénéen français”. En H. Delporte y J. Clottes (eds.): Pyrénées préhistoriques. CTHS. Paris: 243-262.

Utrilla, P. y Montes, L. 2007: “La període 19000-14000 BP dans le bassin de l'Ebre". Bulletin de la Société Préhistorique Française 104: 797-807.

Vaquero, M. (ed.) 2004: Els darrers caçadors-recol-lectors de la Conca de Barberá: el jaciment del Moli del Salt (Vimbodí). Publicacions del Museu Arxiu. Montblanc.
Walker, M.; Björck, S.; Lowe, J. y Cwynar, J. 1999: "Isotopic 'events' in the GRIP ice core: a stratotype for the Late Pleistocene". Quaternary Science Reviews 18: 1143-1150.

Weninger, B.; Jöris, O. y Danzeglocke, U. 2007: CalPal-University of Cologne Radiocarbon Calibration Program Package. http://www.CalPal.de

Weninger. B. y Jöris, O. 2008: "A ${ }^{14} \mathrm{C}$ age calibration curve for the last $60 \mathrm{ka}$ : the Greenland-Hulu U/Th timescale and its impact on understanding the Middle to Upper Paleolithic transition in Western Eurasia". Journal of Human Evolution 55: 772-781.

Yll, E.; Watson, J. y Paz, M.A. 1993: "Les darreres excavacions al Roc del Migdia (Vilanova de Sau, Osona): estat de la qüestió i noves perspectives". Tribuna d'Arqueologia 1992-1993: 15-24. 